\title{
Research on the Influence of Tax Reduction and Administrative Fee Cut on the Upgrading of Industrial Structure in Jilin Province
}

\author{
Shuang Jing \\ Changchun University of Finance and Economics, Changchun, Jilin Province, China \\ "Corresponding author. Email: 497175484@qq.com
}

\begin{abstract}
In recent years, Jilin Province has taken positive actions and serious measures to ensure the implementation of cutting taxes and fees decisions and arrangements on a larger scale, and has achieved remarkable achievements. First of all, in terms of "reduction", we have achieved the reduction of the items that should be reduced, the cut of the items that should be cut, and the withdrawal of the items that should be withdrawn, which not only reduces the tax burden of enterprises, but also brings new impetus to the high-quality economic development of the province; Secondly, in terms of "collection", we should pay more attention to the conservation of tax sources and the prevention of risks while collecting all receivables. As an important strategic plan to promote economic transformation and upgrading, Cutting taxes and fees undoubtedly has a huge impact on the industrial structure. Therefore, this paper mainly analyses the promotion effect of the policy of cutting taxes and fees on the industrial upgrading of Jilin Province from the four driving points of value-added tax, enterprise income tax, individual income tax and social insurance fund, and puts forward countermeasures of cutting taxes and fees to further promote the industrial upgrading in Jilin Province.
\end{abstract}

Keywords: Cutting taxes and fees, Jilin Province, Industrial structure.

\section{INTRODUCTION}

Chinese government has implemented active fiscal policy and increased extra budgetary revenue to make up for the fiscal revenue gap since the 2008 financial crisis, in order to stabilize the development of China's economy; However, the unreasonable scale of government borrowing will reduce the government's regulatory role in the economy, but also bring financial risks to a certain extent and erode the reform dividend (Ziwei LI and Changgui DONG, 2021). Therefore, reasonable tax reduction and administrative fee cut policy based on the supply side comes into being, in order to solve the structural problems in the process of national industrial transformation and upgrading, and actively respond to the changes in the domestic and foreign economic environment. This paper keeps a foothold to serve Jilin Province, focuses on how the tax reduction and administrative fee cut policy improves the enterprise operating environment of Jilin Province, and helps to improve the industrial foundation and strategic upgrading of Jilin Province. Based on this, this paper first analyzes the current tax reduction and administrative fee cut policy and its impact on the economic benefits of Jilin Province, and then analyzes the path of tax reduction and administrative fee cut policy to promote the industrial upgrading of Jilin Province; Finally, the paper puts forward the suggestions of tax reduction and administrative fee cut policy.

\section{THE CURRENT POLICY OF CUTTING TAXES AND FEES AND ITS IMPACT ON ECONOMIC BENEFITS IN JILIN PROVINCE}

The formulation and implementation of tax reduction and administrative fee cut policy can not only reduce the economic pressure, but also meet the personalized requirements of enterprises in the development process, and promote the economic development of Jilin Province. Especially at the beginning of 2020, in the face of the outbreak of COVID-19, the tax reduction and administrative fee cut policy has effectively alleviated the economic downward pressure of Jilin Province. In order to 
actively respond to the impact of COVID-19, we have timely issued tax relief policies to support the development of the real economy, cultivate new momentum and serve small and medium-sized enterprises, which has alleviated the tax pressure on enterprises, effectively promoted social stability and brought about comprehensive economic recovery. According to the results of investigation and research, the tax authorities of Jilin Province have implemented various preferential tax policies during the outbreak of COVID-19 to help enterprises resume work and production. In the first quarter of 2020, the tax reduction and administrative fee cut of a total of RMB 3 billion have been achieved in the province.

\subsection{Value Added Tax Policy and its Effect}

Compared with the turnover tax, the tax on the value-added amount of goods and services circulation is conducive to promoting the cross regional flow of personnel, capital and technology, promoting the fine division of labor, and promoting the structural and strategic transformation of the industry.

For example, for Chang Guang Satellite Technology Co., Ltd., engaged in the high-tech industry, technological innovation is the core competitiveness, and a large amount of R \& D investment is essential. A series of tax reduction and administrative fee cut policies enable enterprises to enjoy the dividend of real money, and promote innovation and development! Benefiting from the preferential policy of VAT rebate, Chang Guang Satellite shared RMB 10.41 million of VAT rebate in 2019 and RMB 6.8 million in 2020, which greatly alleviates the financial pressure of enterprises and provides strong support for technology research and development of enterprise. In addition, from April 1, 2019, the travel expenses of the company's employees meeting the policy requirements can also be included in the input tax for deduction, which reduces the company's taxable amount by RMB 300,000 and the cost of high-tech R \& D and cultivation.

\subsection{Enterprise Income Tax Policy and its Effect}

The tax reduction and administrative fee cut measures for enterprise income tax mainly aim at several enterprises with obvious positive externalities, such as small and micro enterprises, high-tech enterprises, advanced technology service industries, pollution prevention and control and energy conservation and environmental protection enterprises.

For supporting small and micro enterprises, it is proposed to reduce the tax base and tax rate, and raise the recognition standard of annual taxable income to RMB 1 million, which fully reduces the tax burden of small and micro enterprises. For supporting high-tech industries, technologically advanced service industries, pollution prevention and control, energy conservation and environmental protection, a series of preferential policies, such as reducing tax rate to $15 \%$, extending the period of loss carry-over and make-up, increasing the weighted deduction of $\mathrm{R} \& \mathrm{D}$ expenses, expanding the accelerated depreciation of fixed assets, and improving the deduction standard of staff education expenses, are conducive to the innovation and development of hightech enterprises.

For example, Jilin Connell Pharmaceutical Co., Ltd. is a comprehensive modern pharmaceutical enterprise, a key high-tech enterprise in Jilin City, and a key material production enterprise for epidemic prevention and control. During the outbreak of COVID-19, in order to support the epidemic prevention and control, the enterprise has purchased RMB 5.05 million disinfection cabinet and RMB 1.1685 million dispensing tank. According to the regulations of tax reduction and administrative fee cut on deduction of fixed assets, if the unit value of newly purchased equipment and appliances during the period from January 1, 2018 to December 31, 2020 does not exceed RMB 5 million, it is allowed to be included in the current cost at one time and deducted in the calculation of taxable income, and depreciation is not calculated by year; Meanwhile, the one-time deduction preferential of fixed assets can be enjoyed at the time of prepayment declaration. It has reduced the tax payable by more than RMB 900,000 for the enterprise.

\subsection{Individual Income Tax Policy and its Effect}

Measures for personal income tax reduction and administrative fee cut are mainly reflected in five aspects: tax collection mode, taxpayer judgment, tax rate type, expense deduction and tax collection and management.

In the aspect of tax collection, the mode of mixed tax collection is adopted, combining the income from wages and salaries, labor remuneration, manuscript remuneration and royalties into a category of income, and collecting taxes in the final settlement. Taking full account of the taxpayer's ability to pay taxes is conducive to the realization of tax equity. In the aspect of taxpayers, according to international practice, it is determined to shorten the residence time from 365 days to 183 days, which is conducive to the protection of national tax rights and interests. In terms of applicable tax rates, we should expand the tax rate range between middle and low-income groups, and effectively reduce the tax burden of middle and low-income groups. In terms of expense deduction, the amount of tax exemption is increased to RMB 5,000 per month and the added six special additional expense deductions will be conductive to alleviating the gap between the rich and the poor. In terms of tax collection and management, it 
is similar to the provisions on increase of anti-tax avoidance in enterprise income tax to safeguard the national tax rights and interests.

These tax reduction and administrative fee cut policies make all kinds of enterprises in Jilin Province feel the dividend of reform. For example, Chang Guang Satellite Company, a high-tech enterprise, has more than 400 employees, those with master's degree and doctor's degree accounting for about $80 \%$. Based on the new personal income tax policy, the personal income tax burden of the company's employees has been greatly reduced. Up to now, the company has enjoyed nearly RMB 2 million of preferential treatment. Tax reduction and administrative fee cut will provide support for enterprises to retain high-end talents. And these talents are the inexhaustible power source of enterprise innovation.

\subsection{Social Insurance Policy and its Effect}

The social insurance tax reduction and administrative fee cut measures are mainly reflected in payment base based on the average wage of employees in urban units, to re-verify the upper and lower limits of individual social security payment base. Reduce the payment proportion of endowment insurance units at one time, and reduce the payment proportion of unemployment insurance and work-related injury insurance units in stages; Increase the central adjustment proportion of endowment insurance fund; the social security will be collected by the tax authorities.

From the data, we can see that by enjoying the staged reduction and cut policy on half reduction of basic endowment insurance, unemployment insurance, work-related injury insurance and medical insurance issued by Jilin Province, Chang Guang Satellite enterprise will enjoy about RMB 1,370,000 of social insurance reduction and cut and RMB 670,000 of medical insurance reduction and cut in the first quarter of 2020. It is estimated that they will enjoy about RMB $5,500,000$ of social insurance reduction and cut and RMB 2,700,000 of medical insurance reduction and cut this year.

The continued implementation and implementation of the follow-up policies, as well as more tax reduction and administrative fee cut policies, will benefit enterprises and residents in Jilin Province, effectively reduce the burden of enterprises, stimulate production, promote consumption and employment, stimulate market and economic vitality, and restore stable economy.

\section{THE POLICY OF CUTTING TAXES AND FEES PROMOTES THE INDUSTRIAL UPGRADING IN JILIN PROVINCE}

At present, tax reduction and administrative fee cut policy mainly includes inclusive measures and structural measures. Inclusive tax reduction and administrative fee cut covers a wide range, and improves the profit margin of enterprises by reducing the operating costs of enterprise; the structural tax reduction and administrative fee cut are the result of the survival of the fittest by orderly guiding the rational allocation of industrial resources. As an old industrial base in Northeast China, Jilin Province plays an important role in revitalizing the national advanced manufacturing industry and undertaking the task of national food security (Wei DONG, Lin SHI, Wei SONG, 2014). This characteristic determines that the evolution law of industrial structure in Jilin Province must be unique, which is different from those of other provinces under the national overall framework. Therefore, this paper will analyze how tax reduction and administrative fee cut policy promotes the industrial upgrading of Jilin Province by three paths of promoting the upgrading of industrial factors, driving the development of advanced industries, and enhancing the market activity.

From the perspective of promoting the upgrading of industrial factors, the government can reduce taxes and charges on labor, capital, natural resources and other production factors by implementing tax reduction and administrative fee cut policy, relatively reducing the operating costs of enterprises, releasing the profit space of enterprises, and then guiding enterprises to have more surplus funds to innovate technology, enhance the added value of products and realize the value-added of industry. For example, in the first industry of Jilin Province, the emphasis is changed and laid on the improvement of deep processing capacity, realize the development of medium and high level grain products, and gradually make the transition from Jilin grain industry to market-oriented benefit industry;

From the perspective of driving the development of advanced industries, tax reduction and administrative fee cut can not only encourage enterprises to improve their independent $\mathrm{R} \& \mathrm{D}$ and improve innovation ability, but also support micro, small and medium-sized enterprises, help them break market monopoly and enhance survival ability. It can also provide leading enterprises with technical barriers with international competitive advantages, help them expand the upstream and downstream supporting industrial chain and upgrade industrial core technology. For example, the automobile industry in Jilin Province is developing in the forefront of the country, so we can focus on expanding the supporting system of spare parts in Jilin Province by the tax reduction and administrative fee cut 
policy, while the tertiary industry should focus on the development of production-oriented service industry, financial service industry and modern cultural industry with science and technology and education as the core as the strategic leading industry in Jilin Province.

From the perspective of strengthening market activity, tax reduction and administrative fee cut can balance market power, improve business environment for micro, small and medium-sized enterprises, improve competitive vitality of micro, small and medium-sized enterprises, let micro, small and medium-sized enterprises feel the government dividend and maintain the competition pattern within and among industries. At present, the wage level of Jilin Province rounds out the list in the country, which is not commensurate with the GDP ranking. The task of improving people's livelihood is more challenging than other provinces. It must be taken into account in adjusting the industrial structure. However, micro, small and medium-sized enterprises naturally have the advantage of absorbing the majority of employment. Therefore, reducing the tax burden for small, medium and micro enterprises not only has an obvious driving force for their own development, but also helps the social stability of Jilin Province.

\section{SUGGESTIONS ON CUTTING TAXES AND FEES TO PROMOTE THE UPGRADING OF INDUSTRIAL STRUCTURE IN JILIN PROVINCE}

\subsection{Improve the Tax System Reform and Help Build the Development Pattern}

First of all, in terms of value-added tax, the reform of changing three levels into two levels (Ce LIANG, 2021) should be promoted as soon as possible, so as to give full play to the neutral regulation role of valueadded tax on the market and reduce interference. Secondly, we should adjust the tax structure, increase the proportion of enterprise income tax, and reasonably formulate preferential measures of enterprise income tax, such as tax base preferential or tax rate preferential, on the premise of ensuring the government revenue, so as to let enterprises go to the battle-front without any burden and drive the optimization and upgrading of industrial structure. Thirdly, we should speed up the reform of personal income tax, transfer from the current mixed collection mode to the comprehensive collection mode, adopt the family declaration system, fully consider the taxpayer's ability to pay taxes, and shorten the gap between the rich and the poor. Finally, we should unify the social insurance fund as soon as possible, and establish the multi-level social security system combining social horizontal mutual aid and individual vertical security.

\subsection{Accelerating the Tax Informatization Construction and Help Enterprises Develop in High Quality}

Jilin Province should closely follow the pace of national reform, introduce and implement policies and regulations, continue to deepen the reform of "simplifying procedures, decentralizing powers, enhancing supervision and optimizing public services" (Jing ZHANG, 2021), steadily implement the invoice electronization reform, promote the mature and stable development of informatization construction, give full play to the advantages of VAT invoice and other tax big data, and further improve the data service ability for the whole province. In addition, we should crack down on tax related illegal activities of "fake enterprises", "fake exports" and "fake declaration" at a higher level and in a wider field, and accelerate the realization of tax related data sharing by multiple departments. 2021 is the first year of the "14th Five-Year Plan". The tax authorities of Jilin Province should continue to optimize the mechanism and practice of promoting the direct provision of policy dividend to the market subject, pay attention to the preferential tax policies well targeted to high-tech enterprises and talents, and need to solve the problem of "bottleneck" core technology being independent and controllable, which restricts the highquality development of our country.

\section{CONCLUSIONS}

Under the impact of the epidemic situation, the policy of cutting taxes and fees is like timely rain, helping all industries in Jilin Province to tide over difficulties, allowing enterprises to enjoy the benefits of national policies, and opening up a new market for industrial upgrading in Jilin Province. However, although the policy of cutting taxes and fees has a remarkable effect, alleviating the pressure of economic downturn in Jilin Province, alleviating the financial pressure of enterprises, maintaining employment, and effectively promoting social stability and economic recovery, there are still some problems. In the future reform, how to serve the local economic construction using the concept of modern tax governance and big data and how to promote industrial innovation and upgrading using tax means will become the top priority of Jilin Province's tax governance in the "14th FiveYear Plan" period.

\section{ACKNOWLEDGMENTS}

This paper is the staged achievement of Humanities and Social Sciences Research Project of the Education Department of Jilin Province in 2021, "Research on Economic Benefit of Jilin Province Tax Reduction and Administrative Fee Cut Policy" (Contract No.: 
JJKH20211384SK). Xin LIU is the corresponding author.

\section{REFERENCES}

[1] Wei DONG, Lin SHI, Wei SONG. Countermeasures and Suggestions to Promote the Economic Restructuring of Jilin Province [J]. Regional Economy, 2014 (10): 151-152.

[2] Jing ZHANG. Problems and Countermeasures to Cultivate New Kinetic Energy of Jilin Economic Development with High Quality [J]. Northern Economy, 2021 (02): 53-54.

[3] Ziwei LI, Changgui DONG. Research on the Impact of Tax Reduction and Administrative Fee Cut Policies on Industrial Upgrading [J]. Macroeconomics, 2010 (02): 53-55.

[4] Ce LIANG, Tax Reduction and Administrative Fee Cut Promote the High Quality Development of Manufacturing Industry [J]. China Collective Economy, 2021 (11): 70-71. 